${ }^{1}$ Department of Preventive Dentistry, Faculty of Dentistry, Lagos State University College of Medicine, Ikeja, Lagos, Nigeria.

${ }^{2}$ Department of Child Dental Health, Faculty of Dentistry, Lagos State University College of Medicine, Ikeja, Lagos, Nigeria.

${ }^{3}$ Department of Preventive Dentistry, Faculty of Dentistry, University of Medical Sciences, Ondo, Ondo State, Nigeria.

${ }^{4}$ Department of Child Dental Health, Faculty of Dental Sciences, College of Medicine University of Lagos, Nigeria.
Corresponding author:

Afolabi Oyapero

Department of Preventive Dentistry

Faculty of Dentistry,

Lagos State University College of

Medicine, Ikeja, Lagos.

Email:fola_ba@yahoo.com

Received: September 29, 2020

Accepted: November 26, 2020

\section{Association between dental caries, odontogenic infections, oral hygiene status and anthropometric measurements of children in Lagos, Nigeria}

\author{
Afolabi Oyapero ${ }^{1, *}$ (D), Aderinsola Adenaike ${ }^{2}$ (D) , Augustine
} Edomwonyi ${ }^{3}$, Abiola Adeniyi ${ }^{1}$, Olubukola Olatosi ${ }^{4}$

Dental caries is a significant public health problem afflicting about a third of the world's population which impacts nutrition, quality of life and systemic health. Aim: We explored associations between dental caries, odontogenic infections, oral hygiene and anthropometric measurements of children in Lagos, Nigeria. Methods: A pretested validated questionnaire was administered on 278 children who also received anthropometric assessment and dental examinations. Caries was scored according to WHO criteria and untreated dental caries by the Pulpal Exposure, Ulceration, Fistula, Abcess (PUFA/pufa) index. The weight for age (WAZ), height for age (HAZ), and weight for height (WHZ) parameters evaluated nutritional status. Categorical and continuous data were analysed by $\chi^{2}$-test and ANOVA. Regression analysis was done and statistical significance set at $p \leq 0.05$. Results: The prevalence of Decayed, Missing, and Filled Teeth (DMFT $+\mathrm{dmft})>0$ was $220(79.1 \%)$ and the proportion of $\mathrm{d}+\mathrm{D}$ teeth in $\mathrm{dmft}+\mathrm{DMFT}$ index was 194 (70.0\%). The prevalence of odontogenic infections due to caries (PUFA + pufa $>0$ ) was 172 (61.8\%). 74 (26.6\%) children were stunted; 12 (4.3\%) were underweight while 30 (10.8\%) were wasted. Children with PUFA + pufa $>1$ had increased risk of wasting (OR: $2.45 ; 95 \%$ Cl: 1.16-4.88). Children with DMFT+dmft $>5$ were also significantly underweight with odds ratios of $2.34(95 \% \mathrm{Cl}$ 1.04-4.33). Conclusions: There was significant association between untreated dental caries, odontogenic infections and stunting, wasting and being underweight among the children studied. Policy makers should be aware of the additional burden that oral neglect has on anthropometric indices.

Key words: Anthropometry. Body mass index. Dental caries. Dental caries susceptibility. Oral hygiene. 


\section{Introduction}

Dental caries is a significant public health problem afflicting about a third of the world's population with wide ranging impacts on nutrition, quality of life and systemic health ${ }^{1}$. It is a lifelong progressive and cumulative disease, associated with pain and anxiety, time lost from work and school, and when untreated, can lead to hospitalization². The greatest disease burden of dental caries is borne by children in developing countries where health promotion initiatives and access to dental treatment are limited, in an existing milieu of underlying poverty, malnutrition and communicable diseases ${ }^{3}$. In addition to negative impact of dental caries on quality of life, it is also costly to health care systems, accounting for $\leq 10 \%$ of health care budgets in industrialized countries, being the fourth most expensive disease to treat ${ }^{4}$. The cost of treating dental caries is estimated to be US \$3513 per 1000 children in most low-income countries, exceeding the total health budget of these countries ${ }^{5}$. Furthermore, in these low-income countries, oral health policies are usually of low priority, often being completely neglected due to limited resources.

The carious process commences and progresses when oral bacteria metabolize fermentable carbohydrates, producing acids, which diffuse into hard dental tissue, and demineralize tooth enamel. Some authors observed that the frequency of sugar consumption is a stronger predictor of caries risk than the total amount consumed, while others observed that the amount of sugar consumed is more important than consumption frequency ${ }^{6}$. Oral hygiene is likewise crucial for caries prevention, and the likelihood of progression of the carious process is higher when oral hygiene is poor. Thus, the inadequate removal of dental plaque, the frequent intake of sugary foods and drinks and poor access to fluoride in susceptible individuals is invariably linked to caries development and progression?. Consequently, several recent preventive interventions emphasize the maintenance of a favorable oral environment through oral hygiene, restriction of sugar consumption and access to adequate levels of fluoride ${ }^{8}$.

The high prevalence of dental caries is however not only influenced by risk factors like fermentable carbohydrates and a susceptible tooth surface that interact with the causative microorganisms, but other risk indicators such as developmental characteristics at birth, socioeconomic background and access to oral health services $^{9}$. Socio-demographic and behavioral indicators that predispose an individual to increased caries experience include age, gender, educational status, social class, genetic factors and systemic health ${ }^{10}$. Furthermore, certain common risk factors exist between caries and certain systemic condition, such as the frequent ingestion of fermentable sugars, which can also lead to obesity ${ }^{11}$. Researchers have always suspected that a link exists between growth/development and dental caries presumably due to a shared common pathogenesis because nutrition, parenting, lifestyle, physical and social environments, as well as psychosocial factors can influence both conditions $^{12}$. Moreover, untreated dental decay is thought to be a neglected determinant of low Body mass index $(\mathrm{BMI})^{13}$. These research findings that link oral health to general health problems provide an opportunity to put oral health in the agenda of health care policies in low-income developing countries ${ }^{14}$. 
The Decayed, Missing, and Filled Teeth (DMFT) index is a valid tool for assessing the extent and prevalence of dental caries as well as for assessing overall oral health ${ }^{15}$ but it has some limitations due to skewed distributions of caries prevalence in many countries and its inability to assess the consequences of untreated caries. The Pulpal Exposure, Ulcers due to root fragments, Fistula, Abcess (PUFA/pufa) index introduced by Monse et al. ${ }^{16}$. in 2010 complements the DMFT index by displaying the severity of dental decay and quantifying odontogenic infections of the pulp and surrounding tissues due to untreated caries. Many researches that aimed to correlate dental caries with BMI did not account for oral hygiene and did not stratify caries based on the PUFA index. It is necessary to do this because it is neglected and untreated dental caries that often results in pain and discomfort that may affect ability to chew and ultimately nutrition. Although evidence on the probable effect of untreated dental caries is receiving attention in developed countries, in developing countries, the impact of untreated dental caries on malnutrition and well-being is not adequately researched, with no such study documented in Nigeria. This study thus aimed to determine the relationship between caries risk, untreated dental caries (PUFA), oral hygiene and the anthropometric measurements of children at a Tertiary Paediatric Dental Clinic in Lagos, Nigeria.

\section{MATERIALS AND METHODS}

Ethical considerations: Ethical approval for the study was obtained from the Health Research and Ethics Committee of the Lagos State University Teaching Hospital, Ikeja (LREC/06/10/1415). The study was implemented in line with the declarations of Helsinki and the confidentiality of all the participants was assured by the researchers.

Study design and study population: This was a descriptive study conducted among paediatric patients that presented for treatment at the Child Dental Health Clinic after they were referred for treatment from the oral diagnosis clinic of the Lagos State University Teaching Hospital, Ikeja, Lagos, Nigeria (LASUTH). LASUTH is a tertiary teaching hospital in the cosmopolitan city of Lagos. Lagos State University Teaching Hospital is an urban tertiary center located in the heart of Lagos, Nigeria. It serves as a referral center for public and private hospitals in Lagos and her neighboring states.

Sample Size: A confidence interval of $95 \%$ was used for the sample size calculation, with an absolute precision of 0.05 and with a standard error of $2 \%$ or less; using a recent Nigerian caries prevalence $(p=20.4 \%)^{17}$, a minimum sample size of 240 was required. We however 272 recruited for the study to make provision for incomplete data.

Inclusion and exclusion criteria: The inclusion criteria was children and adolescents aged 4-16 years of both genders whose parents agreed to participate in the study and who gave informed consent and assent where appropriate. Children with physical or mental disability with such conditions that have difficulty in managing routine oral hygiene measures and hence are more prone to dental caries, those with any developmental dental anomaly and those with ongoing dental treatment were excluded.

Sampling technique: Our study sample was obtained by a systematic random sampling technique. We randomly selected every third patient on the attendance register 
after balloting for the starting point. We planned to recruit 6 patients per clinic day, given that about 20 patients are booked for each session. They were recruited on each Wednesday and Friday Paediatric Dentistry clinic day until the required sample size was attained.

\section{Study procedure}

Study instrument: An interviewer administered questionnaire was utilized for data collection. Data on the socio-demographic profile was obtained from the caregiver of each study participant. These included information on the age, gender, as well as maternal and paternal education and occupation. Oral health-related behaviour related to dietary habits, oral hygiene practices and past dental visits was also obtained. Anthropometric measures were then taken and clinical examinations were conducted to determine the dental caries status.

Standardisation of examiners: The intra- and inter-examiner-reproducibility was assessed by the kappa ( $\mathrm{k}$ ) statistics. Calibration of examiners (two dental resident doctors) was done by a Consultant Community Dentist. Duplicate examinations were taken on 20 randomly selected children in the oral diagnosis unit to evaluate intra-examiner and inter-examiner reproducibility. The $\mathrm{k}$ values for inter-examiner-reproducibility ranged from 0.88 (O.A.) to 0.90 (A.A.) for the PUFA/pufa index, and between from 0.92 (O.A.) to 0.93 (A.A.) for the DMFT/dmft index. Intra-examiner reproducibility ranged from 0.91 to 1.00 (O.A.) and between 0.92 to 1.00 (A.A.) for both indices.

Anthropometric measures: The height of the children standing upright and without shoes was measured with a portable stadiometer (Seca 216 Height Rod; Seca GmbH \& Co. KG, Hamburg, Germany) to the nearest $0.5 \mathrm{~cm}$. Weight was measured with children wearing light outfit using an electronic digital scale (Soehnle Gala XL; leifheit AG, Nassau, Germany) to the nearest $0.5 \mathrm{~kg}$. The measuring equipment was re-calibrated daily and all measurements were done by a well-trained nurse following standardized guidelines. The measuring equipment was re-calibrated daily.

Oral examinations: Oral examinations were done using plane mouth mirrors and blunt dental probes oral examination. When an active or restored carious cavity or extracted tooth due to caries was detected on manual inspection, it was recorded as caries on the dental charts using the DMFT+dmft index. PUFA+pufa was used to record the presence of a visible pulp $(\mathrm{P} / \mathrm{p})$, ulceration of the oral mucosa due to root fragments $(U / U)$, a fistula $(F / f)$ or an abscess $(A / a)$ resulting from untreated caries in the primary (pufa) and permanent (PUFA) dentition for the presence of either the PUFA+pufa and DMFT+dmft score per child was calculated in the a cumulative way without any dichotomy.

Data entry and analysis: Data was analysed with SPSS version 22.0 (IBM, Armonk, NY). Mean DMFT+dmft score for both primary and permanent dentition was reported together. Untreated dental caries severity was recorded using PUFA+pufa index and reported together as mean scores. Caries prevalence and overall PUFA+pufa prevalence was calculated as a percentage. The weight for age (WAZ), height for age (HAZ), and weight for height (WHZ) parameters were calculated using WHO Epi 3.5 nutritstat software. Using age and gender specific criteria, children were categorized as 
being at significant risk for either inadequate (<-2 SD) or excessive ( $>+2$ SD) growth. Nutritional status, an independent variable, was regrouped, stunting was defined as $H A Z<-2.0$, thinness as WAZ $<-2.0$, overweight as WAZ $>1.0$ and obesity as WAZ $>2.0$. Frequency tables were generated for all variables and mean scores computed for numerical variables. The correlation between dmft and pufa scores was computed by the Spearman's rank correlation coefficient $(\rho)$. Categorical data were compared between groups using the chi-square test and continuous data were analyzed by t-test and ANOVA. Logistic regression model controlled for variables that showed statistical significance $(P<0.05)$ in bi-variate analysis with low BMI as dependent variable. The probability level of $p<0.05$ was considered statistically significant.

\section{RESULTS}

Out of the 278 children seen, 146 (52.5\%) were female, the highest proportion (116; $41.7 \%$ ) were aged between 6-10 years and the mean age was $8.82 \pm 3.4$ yrs. Mean maternal age was $36.45 \pm 3.22$; most $(180 ; 64.7 \%)$ were of the middle social class and $212(76.8 \%)$ of mothers had $\geq 12$ years of formal education. For Caries Risk factors and Indicators, the children consumed carbonated drinks and beverages an average of $2.14 \pm 2.26$ times per week and Cookies, biscuits or sweets $3.65 \pm 2.54$ times per week. 74(26.6\%) children has poor oral hygiene while 209(75.2\%) had No Dental Home or previous dental visits. $48(17.3 \%)$ children had enamel hypoplasia. Maternal educational level, social class, number of children in the family, consumption of cariogenic meals, poor oral hygiene and history of dental visits were all significantly associated with dmft+DMFT and pufa+PUFA values $(p<0.05)$. (Table 1)

Table 1. Demographic Characteristics, caries risk indicators and caries status of the sample.

\begin{tabular}{|c|c|c|c|}
\hline Category & $\begin{array}{c}\text { Mean } \pm \text { SD or } \\
\text { No. }(\%)\end{array}$ & $\begin{array}{c}\mathrm{dmft}+\mathrm{DMFT} \\
\chi^{2} ; p \text { value }\end{array}$ & $\begin{array}{l}\text { pufa+PUFA; } \\
\chi^{2} ; p \text { value }\end{array}$ \\
\hline Children's demographics $n=278$ & & & \\
\hline Male & $\begin{array}{c}132(47.5) \\
\text { DMFT }=\text { dmft } \geq 1: \\
99(75.0)\end{array}$ & $25.20 ; 0.406$ & $5.88 ; 0.437$ \\
\hline Female & $\begin{array}{c}146(52.5) \\
\text { DMFT }=d m f t \geq 1: \\
121(82.9)\end{array}$ & & \\
\hline Age, y & $8.82 \pm 3.4$ & $8.45 ; 0.207$ & $6.25 ; 0.396$ \\
\hline $1.0-5.0$ & $52(18.7)$ & & \\
\hline $6.0-10.0$ & $116(41.7)$ & & \\
\hline $11.0-15.0$ & $110(39.6)$ & & \\
\hline \multicolumn{4}{|l|}{ Parents' demographics } \\
\hline Age, y & $36.45 \pm 3.22$ & & \\
\hline Length of formal education, $y$ (mean) & $13.35 \pm 3.49$ & & \\
\hline$<12$ years of formal education (mum) & $66(23.2)$ & $11.65 ; 0.039 * *$ & $6.22 ; 0.027^{* *}$ \\
\hline$\geq 12$ years of formal education (mum) & $212(76.8)$ & & \\
\hline Survey respondent is the mother & $268(96.4)$ & & \\
\hline
\end{tabular}


Continuation

\begin{tabular}{|c|c|c|c|}
\hline \multicolumn{4}{|l|}{ Social Class } \\
\hline Lower & $40(14.4)$ & $4.67 ; 0.014^{\star \star}$ & $3.55 ; 0.012^{\star \star *}$ \\
\hline Middle & $180(64.7)$ & & \\
\hline Upper & $58(20.9)$ & & \\
\hline Number of children & & $4.45 ; 0.028^{* *}$ & $6.70 ; 0.012^{\star *}$ \\
\hline $1-4$ & $226(81.3)$ & & \\
\hline $5-8$ & $52(18.7)$ & & \\
\hline \multicolumn{4}{|l|}{ Caries Risk factors and Indicators } \\
\hline Carbonated drinks and beverages times/wk & $2.14 \pm 2.26$ & & \\
\hline Never or rarely & $54(19.5)$ & $4.09 ; 0.000 * *$ & $4.23 ; 0.000 * *$ \\
\hline Weekly or more frequently & $56(20.1)$ & & \\
\hline Daily or more frequently & $168(60.4)$ & & \\
\hline Cookies, biscuits or sweets times/wk & $3.65 \pm 2.54$ & & \\
\hline Never or rarely & $56(20.1)$ & $2.88 ; 0.014^{\star *}$ & $1.72 ; 0.001^{\star *}$ \\
\hline Weekly or more frequently & $84(30.2)$ & & \\
\hline Daily or more frequently & $138(50.8)$ & & \\
\hline Use of Fluoridated toothpaste (No) & $98(35.3)$ & $2.52 ; 0.281$ & $4.09 ; 0.129$ \\
\hline Child has poor oral hygiene; visible plaque & $74(26.6)$ & $2.49 ; 0.012^{\star \star}$ & $1.83 ; 0.016^{\star *}$ \\
\hline Child has enamel hypoplasia & $48(17.3)$ & $1.032 ; 0.59$ & $1.217 ; 0.54$ \\
\hline No Dental Home or previous dental visits & $209(75.2)$ & $2.75 ; 0.025^{\star *}$ & $4.23 ; 0.020 * *$ \\
\hline Mother or sibling has un-restored cavities & $42(15.1)$ & $1.62 ; 0.032^{\star \star}$ & $1.02 ; 0.044^{\star *}$ \\
\hline Impaired salivary flow & $8(2.9)$ & & \\
\hline
\end{tabular}

** Significant

The overall prevalence of caries (DMFT $+\mathrm{dmft}>0$ ) was $79.1 \%$ ) while the overall prevalence of odontogenic infections due to caries (PUFA + pufa > 0) was 61.8\%. Decayed teeth (d/D) accounted for $70 \%$ in DMFT + dmft and the mean no. of decayed teeth $(\mathrm{dt} / \mathrm{DT} \mathrm{x} \pm \mathrm{SD}$ ) was $3.01 \pm 2.34$. Mean dmft+DMFT score was $3.63 \pm 3.18$ and $112(40.3 \%)$ of the children had dmft+DMFT scores $>5$. The mean pufa+PUFA score was $2.42 \pm 1.95$ and pulp exposure accounted for the highest proportion (mean $p x \pm S D=1.98 \pm 1.54)$. For Child nutritional outcomes, $74(26.6 \%)$ children were stunted, 12 (4.3) were underweight and 30 (10.8) were wasted. (Table 2)

Table 2. Child oral health outcomes and nutritional parameters.

\begin{tabular}{lcc}
\hline Variables & & \\
\hline Categories & $\begin{array}{c}\text { Mean } \pm \text { SD or No. } \\
(\%)\end{array}$ & Valid No. \\
\hline Has any tooth decay (yes) & $220(79.1)$ & 278 \\
\hline Proportion of d teeth in dmft+DMFT index (d/D) & $194(70.0)$ & \\
\hline decayed teeth (dt/DT $x \pm$ SD) & $3.01 \pm 2.34$ & \\
\hline Missing teeth $(\mathrm{mt} / \mathrm{MT} \mathrm{x} \pm \mathrm{SD})$ & $0.55 \pm 1.13$ & \\
\hline
\end{tabular}


Continuation

\begin{tabular}{|c|c|}
\hline Filled teeth (ft/FT $x \pm S D$ ) & $0.07 \pm 0.18$ \\
\hline \multicolumn{2}{|l|}{ Severity of dental caries } \\
\hline $\mathrm{dmft}+\mathrm{DMFT}=0$ & $58(20.9)$ \\
\hline $\mathrm{dmft}+\mathrm{DMFT}=1-5$ & $108(38.8)$ \\
\hline $\mathrm{dmft}+\mathrm{DMFT}>5$ & $112(40.3)$ \\
\hline Average dmft+DMFT score & $3.63 \pm 3.18$ \\
\hline \multicolumn{2}{|l|}{ Care index (\%) } \\
\hline \multicolumn{2}{|l|}{ Pulp involved decayed teeth } \\
\hline Yes (pufa+PUFA prevalence) & $172(61.8)$ \\
\hline pufa+PUFA $(x \pm S D)$ & $2.42 \pm 1.95$ \\
\hline Pulp exposure $(p \times \pm S D)$ & $1.98 \pm 1.54$ \\
\hline Ulceration ( $\mathrm{u} x \pm \mathrm{SD})$ & $0.0 \pm 0.00$ \\
\hline Fistula $(f x \pm S D)$ & $0.11 \pm 0.12$ \\
\hline Abcess $(\mathrm{a} x \pm \mathrm{SD})$ & $0.33 \pm 0.46$ \\
\hline \multicolumn{2}{|l|}{ Child nutritional outcomes } \\
\hline \multicolumn{2}{|l|}{ Undernourished status $^{\mathrm{a}}$} \\
\hline Height for age (stunted), no. & $74(26.6)$ \\
\hline Height for age (stunted), z-score & $1.81 \pm 0.6$ \\
\hline Weight for age (underweight), no. & $12(4.3)$ \\
\hline Weight for age (underweight), z-score & $-0.19 \pm 1.4$ \\
\hline BMI for age (wasted), no. & $30(10.8)$ \\
\hline BMI for age (wasted), z-score & $0.2 \pm 2.8$ \\
\hline \multicolumn{2}{|l|}{ Overweight status } \\
\hline No. & $50(19.9)$ \\
\hline z-score & $0.2 \pm 2.8$ \\
\hline
\end{tabular}

There was a low positive correlation between poor oral hygiene and dental caries severity $(\rho=0.307 ; P=0.005)$ and a moderate positive correlation between caries severity and odontogenic infection $(\rho=0.604 ; P<0.001)$. We likewise found significant associations between the severity of the children's carries experience and their anthropometric measurements. For children with the high-severity caries group, the mean height-for-age, weight for age- and BMI-for-age $z$-scores were -0.36 (95\% $\mathrm{Cl}-1.12,-0.67)$; $-0.53(95 \% \mathrm{Cl}-0.62,-0.17)$ and -1.03 (95\% Cl-0.58, -0.16) lower, respectively, than those in the caries-free children. Similarly, for children with $>1$ odontogenic infection, the mean height-for-age, weight for age- and BMI-for-age $z$-scores were $-0.79(-1.88,-1.17) ;-0.75(-1.01,-0.62)$ and $-0.65(-0.62,0.20)$ lower than in children with no odontogenic infection. (Table 3) 
Table 3. Bivariate Analysis between caries indices and Nutritional parameters.

\begin{tabular}{|c|c|c|c|c|c|}
\hline Predictive Variable & $\begin{array}{l}\text { Outcome } \\
\text { Variable }\end{array}$ & $\begin{array}{l}\text { Correlation } \\
\text { Factor }(\rho) \text { or } \\
\text { Test Statistic } \\
\text { ( F) }\end{array}$ & $\begin{array}{c}\text { mean } \\
\text { z-score }\end{array}$ & $\begin{array}{c}\text { Mean } \\
\text { Difference From } \\
\text { Reference } \\
(95 \% \mathrm{Cl})\end{array}$ & $P$ \\
\hline $\begin{array}{l}\text { Poor Oral Hygiene } \\
\text { (DI score }>1.5 \text { ) }\end{array}$ & $\begin{array}{c}\text { Mean } \\
\text { dmft+DMFT }\end{array}$ & $\rho=0.307$ & & & $0.005^{\star *}$ \\
\hline Mean dmft+DMFT & $\begin{array}{c}\text { Mean } \\
\text { pufa+PUFA }\end{array}$ & $\rho=0.645$ & & & $<0.001^{* \star}$ \\
\hline $\mathrm{dmft}+\mathrm{DMFT}=0$ & $\begin{array}{l}\text { Mean height } \\
\text { for age } \\
\text { (stunting) }\end{array}$ & $F=1.88$ & $-0.58 \pm 3.5$ & (Ref) & \\
\hline $\mathrm{dmft}+\mathrm{DMFT}=1-5$ & & & $-0.69 \pm 3.9$ & $\begin{array}{c}-0.11 \\
(-0.83,-0.35)\end{array}$ & 0.042 \\
\hline dmft+DMFT > 5 & & & $-0.94 \pm 2.7$ & $\begin{array}{c}-0.36 \\
(-1.12,-0.67)\end{array}$ & 0.001 \\
\hline $\mathrm{dmft}+\mathrm{DMFT}=0$ & $\begin{array}{l}\text { Mean weight } \\
\text { for age } \\
\text { (underweight) }\end{array}$ & $F=6.38$ & $-0.08 \pm 1.2$ & (Ref) & \\
\hline $\mathrm{dmft}+\mathrm{DMFT}=1-5$ & & & $-0.26 \pm 1.8$ & $\begin{array}{c}-0.34 \\
(-0.41,-0.88)\end{array}$ & 0.031 \\
\hline $\mathrm{dmft}+\mathrm{DMFT}>5$ & & & $-0.45 \pm 1.4$ & $\begin{array}{c}-0.53 \\
(-0.62,-0.17)\end{array}$ & 0.002 \\
\hline $\mathrm{dmft}+\mathrm{DMFT}=0$ & $\begin{array}{l}\text { Mean BMI for } \\
\text { age(wasting) }\end{array}$ & $F=14.8$ & $0.64 \pm 2.3$ & (Ref) & \\
\hline $\mathrm{dmft}+\mathrm{DMFT}=1-5$ & & & $0.23 \pm 3.2$ & $\begin{array}{c}-0.41 \\
(0.09,0.38)\end{array}$ & 0.003 \\
\hline $\mathrm{dmft}+\mathrm{DMFT}>5$ & & & $-0.39 \pm 2.6$ & $\begin{array}{c}-1.03 \\
(-0.58,-0.16)\end{array}$ & 0.000 \\
\hline pufa + PUFA $=0$ & $\begin{array}{l}\text { Mean height } \\
\text { for age } \\
\text { (stunting) }\end{array}$ & $F=0.745$ & $-0.58 \pm 3.5$ & (Ref) & \\
\hline pufa + PUFA $=0.1-1$ & & & $-0.75 \pm 2.8$ & $\begin{array}{c}-0.17 \\
(-0.96,-0.53)\end{array}$ & 0.478 \\
\hline pufa+PUFA $>1$ & & & $-1.37 \pm 1.2$ & $\begin{array}{c}-0.79 \\
(-1.88,-1.17)\end{array}$ & 0.019 \\
\hline pufa $+P U F A=0$ & $\begin{array}{l}\text { Mean weight } \\
\text { for age } \\
\text { (underweight) }\end{array}$ & $F=0.745$ & $-0.08 \pm 1.2$ & (Ref) & \\
\hline pufa $+P U F A=0.1-1$ & & & $-0.28 \pm 1.6$ & $\begin{array}{c}-0.20 \\
(-0.51,-0.91)\end{array}$ & $0.004 * \star$ \\
\hline pufa+PUFA 1 & & & $-0.83 \pm 1.1$ & $\begin{array}{c}-0.75 \\
(-1.01,-0.62)\end{array}$ & $<0.001$ \\
\hline pufa $+P U F A=0$ & $\begin{array}{l}\text { Mean BMI for } \\
\text { age (wasting) }\end{array}$ & $F=1.87$ & $0.23 \pm 3.2$ & (Ref) & \\
\hline pufa + PUFA $=0.1-1$ & & & $0.67 \pm 2.3$ & $\begin{array}{c}-0.44 \\
(0.51,0.86)\end{array}$ & 0.018 ** \\
\hline pufa+PUFA> 1 & & & $-0.42 \pm 4.3$ & $\begin{array}{c}-0.65 \\
(-0.62,0.20)\end{array}$ & $<0.001$ \\
\hline
\end{tabular}

F= ANOVA $\rho=$ Spearman rank correlation. 
Table 4 displays the Odds ratio and Confidence Interval values obtained from the logistic regression model between significant predictor variables in the bivariate analysis and outcome variable (low BMI). Maternal education of $<12$ years of formal education - OR 0.52 (Cl 0.03-1.21) and $p=0.015$; Social Class: Middle OR 0.41 (Cl 0.17-0.72) and $p<0.008$ and Upper OR 0.38 (Cl 0.13-0.69) and $p=0.001$; dmft+DMFT 1- 5 OR 0.83 $(\mathrm{Cl} 0.89-3.97)$ and $p=0.027$ and pufa+PUFA $=0.1-1$ OR $98(\mathrm{Cl} 1.0-2-4.43)$ and $p=0.008$ - also showed significantly more likelihood to be associated with low BMI.

Table 4. Odds ratio from the logistic regression model between significant predictor variables in the bivariate analysis and outcome variable (low BMI).

\begin{tabular}{|c|c|c|c|}
\hline \multirow[b]{2}{*}{ Variables } & \multicolumn{3}{|c|}{ Mean BMI for age (wasting) } \\
\hline & Odds ratio & $\begin{array}{l}\text { Confidence } \\
\text { Interval }\end{array}$ & P-value \\
\hline \multicolumn{4}{|l|}{ Maternal education } \\
\hline$<12$ years of formal education & 1 & & \\
\hline$\geq 12$ years of formal education & 0.52 & $0.03-1.21$ & 0.015 \\
\hline \multicolumn{4}{|l|}{ Social Class } \\
\hline Lower & 1 & & \\
\hline Middle & 0.41 & $0.17-0.72$ & 0.008 \\
\hline Upper & 0.38 & $0.13-0.69$ & 0.001 \\
\hline \multicolumn{4}{|l|}{ Number of children } \\
\hline $1-4$ & 1 & & \\
\hline $5-8$ & 1.65 & $0.78-3.23$ & 0.043 \\
\hline \multicolumn{4}{|c|}{ Severity of dental caries (dmft+DMFT) } \\
\hline $\mathrm{dmft}+\mathrm{DMFT}=0$ & 1 & & \\
\hline $\mathrm{dmft}+\mathrm{DMFT}=1-5$ & 1.83 & $0.89-3.97$ & 0.027 \\
\hline dmft+DMFT > 5 & 2.34 & $1.04-4.33$ & 0.005 \\
\hline \multicolumn{4}{|c|}{ Pulp involved decayed teeth (PUFA+pufa) } \\
\hline pufa+PUFA=0 & 1 & & \\
\hline pufa+PUFA= 0.1-1 & 1.98 & $1.02-4.43$ & 0.008 \\
\hline pufa+PUFA> 1 & 2.45 & $1.16-4.88$ & 0.001 \\
\hline \multicolumn{4}{|l|}{ Oral Hygiene Index (OHI) } \\
\hline Poor & 1 & & \\
\hline Fair & 0.87 & $0.41-1.63$ & 0.453 \\
\hline Good & 0.71 & $0.33-1.45$ & 0.074 \\
\hline
\end{tabular}

\section{DISCUSSION}

The development of dental caries in children encompasses a multifaceted interaction between infectious, genetic, biochemical, social and physical environmental, and behavioral factors which also have implications for systemic health. Females constituted a higher proportion of children with caries in our study, confirming the observation by previous authors that the odds of being susceptible to caries is higher in girls ${ }^{18}$. 
This has been adduced to the early hormonal fluctuation in girls, compared with boys and the fact that the permanent dentition of girls erupts two to 10 months earlier than that of boys ${ }^{19}$.

The children were observed to consume carbonated drinks and beverages an average of $2.14 \pm 2.26$ times per week and Cookies, biscuits or sweets $3.65 \pm 2.54$ times per week. Those who consumed more cariogenic meals had significantly more carious teeth and odontogenic infections. Sheiham and James ${ }^{20}$ documented a dose-response relationship, between the caries process and sugar consumption. About $18 \%$ of our study subjects also had enamel hypoplasia. A defective tooth surface could provide a suitable site for the adhesion and colonisation of cariogenic bacteria, and the progress of caries can depend on the degree of surface defect or alterations. The ensuing cleaning difficulties may cause bacteria to be retained at the base of the defect resulting in a more rapidly developing carious lesion than otherwise would occur on a sound tooth surface.

We also observed a low positive correlation between poor oral hygiene and dental caries severity which is in agreement with what was reported by other research$\mathrm{ers}^{2}$. A recent meta-analysis identified a 1.5-fold higher risk of dental caries among people brushing less than once daily compared to those brushing twice daily. (odds ratio $(\mathrm{OR})=1.56 ; 95 \% \mathrm{Cl} 1.37-1.78)^{21}$ Streptococcus mutans acting with a group of other microorganisms have been implicated in the initiation and progression of dental caries ${ }^{22}$. Tooth brushing is the most effective method of mechanical plaque control which simultaneously delivers fluoride topically through toothpaste. Oral health promotion programs constantly underscore the importance of tooth brushing while most evidence based preventive interventions emphasize plaque control, restriction of sugar consumption, and adequate exposure to topical fluoride delivery systems.

We also observed a significant association between low maternal educational attainment, lower social class and many children in the family with high caries experience. This was similarly observed by other researchers who observed that unfavorable socioeconomic status, including lower parental educational level and household income, was demonstrated to affect children's oral health ${ }^{23}$. Dietary habits and conditions that are influenced by life style like dental caries, overweight, obesity, and malnutrition are shown to covary with socioeconomic status ${ }^{24}$. Overall, caries prevalence has waned in most populations, but socioeconomic disparities increasingly define dissimilarities observed among these populations with caries transiting from a disease of affluence to a disease of deprivation ${ }^{25}$. It has been postulated that people from lower socio-economic backgrounds have poorer access oral health information and dental services.

The overall prevalence of caries in our study population was high at $79.1 \%$ with decayed teeth accounting for $70 \%$ of $\mathrm{dmft+DMFT}$ scores, though it was a hospital based study group. Offering only dmft data to policy makers however leaves them unmindful of the severity and related consequences of untreated caries on oral and systemic health ${ }^{26}$. The overall prevalence of odontogenic infections due to caries (mainly pulp exposure) was also high at $61.8 \%$. The PUFA/pufa prevalence in different countries vary from $24 \%$ in Brazilian 6- to 7-year-olds ${ }^{27}$ to $85 \%$ in 6-year-old children from the Philippines ${ }^{16}$, indicating a high occurrence of untreated dental caries and dental neglect. 
Teeth with pulp exposure cause significant discomfort and pain which diminishes the ability of the child to take on the task of a full day of school. It also reduces concentration and energy, the ability to eat healthy food and leads to malnutrition. It is also associated with sleeping problems, learning disorders and absence from school as well as chewing difficulties potentially impacting on children's, nutrition, growth and body weight. Persistent pain also causes the child to lose school hours, and when in school, the time spent is markedly less productive ${ }^{28}$. This is because pain interferes with the ability of the child to concentrate. Therefore, oral health fundamentally influences children's general health and quality of life. Additionally, odontogenic infections can progress to dentoalveolar abcess and ludwigs angina, a frequently cited reason for the hospitalisation of young children ${ }^{29}$. Thus, children with pufa scores should be characterized to be at high caries risk for early caries onset in permanent teeth.

We observed a moderate positive correlation between caries severity and odontogenic infection. Regarding Child nutritional outcomes, $26.6 \%$ of the children were stunted, $4.3 \%$ were underweight and $10.8 \%$ were wasted. We likewise found significant associations between the severity of the children's carries experience and their anthropometric measurements. Numerous researches with inconsistent findings have observed an association between caries experience and anthropometric measurements in children due to differences in study designs and internal or external validity influences ${ }^{30}$. Some researchers observed a strong association between obesity and a high caries experience ${ }^{31}$ while Sheller et al ${ }^{32}$. observed no association. Others however reported an inverse relationship ${ }^{33}$. There is a complex interplay of many variables that can produce divergent and bi-directional outcomes depending on the population studied. Overweight or obese children also have relatively high levels of dental caries due to the consumption of high levels of soda and other energy-dense foods, which are cariogenic and obesogenic. Protein-energy malnutrition in children in indigent populations can also result in reduced salivary flow and a high count of lactobacilli and Streptococcus mutans, as well as altered saliva composition and impaired secretion, predisposing to dental caries ${ }^{34}$. Conversely, reduced chewing ability due to caries can negatively impact affect nutritional intake which further exacerbates susceptibility to dental caries.

It should however be pointed out that in developing countries like ours, the high prevalence of dental caries is closely related to poverty and low socioeconomic status. Malnutrition of children is highly prevalent in low-income and middle-income countries, resulting in substantial increases in mortality and overall disease burden. To establish internal validity, we controlled for socioeconomic and behavioural factors and still observed a significant association between being underweight and dental caries. The implication of our research is emphasizing the added burden that caries possess on the abysmal health indices in developing countries, aside the intense scourge of HIV/AIDS in addition to the rising prevalence of non-communicable diseases (NCDs) like hypertension, diabetes mellitus, and other medical conditions.

Decision and policy makers should be made aware of the additional burden that oral neglect can have on the anthropometric indices of children. The identification of high-risk groups provides motivation to enhance community awareness and its 
involvement in preventive efforts; as well as re-orient oral health services towards oral health promotion and prevention. Prevention strategies through early institution of dental home include dietary modifications to reduce high sweetener consumption, supervised tooth brushing, systemic fluoride supplements for children living in areas without public health fluoridation, and professional delivery of fluoride varnish and sealants ${ }^{35}$. Thus, multiple strategies encompassing both upstream and downstream preventive approaches are now required to translate the recommendations into policy and practice.

\section{Study limitations}

Apart from being one of the only study that determined that correlated untreated dental caries using the PUFA index with BMI in Nigeria, the other strength of our study lies in our exploration of the impact of oral hygiene on caries experience. This investigation, however, had a number of limitations. One is non-use of radiographs in identification of caries in the schools, even though we adhered to the WHO protocol for clinical diagnosis. Secondly, we used a hospital based cohort rather than obtaining our sample from the community. Nevertheless, within the limits of our study design, the data provides useful information for further empirical studies on subsets of the population that still have a high caries experience.

\section{Conclusions}

There was a significant association between untreated dental caries, odontogenic infections and stunting, wasting and being underweight among the children studied. We observed a high prevalence of Decayed, Missing, and Filled Teeth of which the proportion of decayed teeth was $70.0 \%$. The overall prevalence of odontogenic infections due to caries was also high (61.8\%). There was a significant correlation between poor oral hygiene and untreated caries. Children with PUFA + pufa $>1$ had an increased risk of wasting while those with $\mathrm{DMFT}+\mathrm{dmft}>5$ were significantly underweight.

\section{REFERENCES}

1. Vos T, Flaxman AD, Naghavi M, Lozano R, Michaud C, Ezzati M, et al. Years lived with disability (YLDs) for 1160 sequelae of 289 diseases and injuries 1990-2010: a systematic analysis for the Global Burden of Disease Study 2010. Lancet. 2012 Dec;380(9859):2163-96. doi: 10.1016/S0140-6736(12)61729-2.

2. Moynihan P. Sugars and dental caries: evidence for setting a recommended threshold for intake. Adv Nutr. 2016 Jan;7(1):149-56. doi: 10.3945/an.115.009365.

3. Black RE, Victora CG, Walker SP Bhutta ZA, Christian P, de Onis M et al. Maternal and child undernutrition and overweight in low-income and middle-income countries. Lancet. 2013 Aug;382(9890):427-51. doi: 10.1016/S0140-6736(13)60937-X.

4. Marcenes W, Kassebaum NJ, Bernabe E, Flaxman A, Naghavi M, Lopez A, et al. Global burden of oral conditions in 1990-2010: a systematic analysis. J Dent Res. 2013 Jul;92(7):592-7. doi: $10.1177 / 0022034513490168$.

5. Yee R., Nepal K., Sheiham A. The burden of restorative dental treatment for children in Third World countries. Int Dent J. 2002;52(1):1-9. 
6. Bernabé E, Vehkalahti MM, Sheiham A, Lundqvist A, Suominen AL. The shape of the doseresponse relationship between sugars and caries in adults. J Dent Res. 2016 Feb;95(2):167-72. doi: 10.1177/0022034515616572.

7. Adeniyi AA, Oyapero OA, Ekekezie OO, Braimoh MO. Dental caries and nutritional status of school children in Lagos, Nigeria - a preliminary survey. J West Afr Coll Surg. 2016;6(3):15-38.

8. Adair PM, Burnside G, Pine CM. Analysis of health behaviour change interventions for preventing dental caries delivered in primary schools. Caries Res. 2013;47 Suppl 1:2-12. doi: 10.1159/000351829.

9. Anil S, Anand PS. Early childhood caries: prevalence, risk factors, and prevention. Front Pediatr. 2017 Jul 18:5:157. doi: 10.3389/fped.2017.00157.

10. Declerck D, Leroy R, Martens L, Lesaffre E, Garcia-Zattera MJ, Broucke VS, et al. Factors associated with prevalence and severity of caries experience in preschool children. Community Dental Oral Epidemiol. 2008 Apr;36(2):168-78. doi: 10.1111/j.1600-0528.2007.00385.x.

11. Alshihri AA, Rogers HJ, Alqahtani MA, Aldossary MS. Association between dental caries and obesity in children and young people: a narrative review. Int J Dent. 2019 May 2;2019:9105759. doi: 10.1155/2019/9105759.

12. Spiegel KA, Palmer CA. Childhood dental caries and childhood obesity: different problems with overlapping causes. Am J Dent. 2012 Feb;25(1):59-64.

13. Benzian H, Monse B, Heinrich-Weltzien R, Hobdell M, Mulder J, van Palenstein Helderman W. Untreated severe dental decay: a neglected determinant of low body mass index in 12-year-old Filipino children. BMC Public Health. 2011 Jul 13;11:558. doi: 10.1186/1471-2458-11-558.

14. Mishu MP, Hobdell M, Khan MH, Hubbard RM, Sabbah W. Relationship between untreated dental caries and weight and height of 6- to 12-year-old primary school children in Bangladesh. Int J Dent. 2013;2013:629675. doi: 10.1155/2013/629675.

15. Dye BA, Tan S, Smith V, Lewis BG, Barker LK, Thornton-Evans G, et al. Trends in oral health status: United States, 1988-1994 and 1999-2004. Vital Health Stat 11. 2007 Apr;(248):1-92.

16. Monse B, Heinrich-Weltzien R, Benzian H, Holmgren C, Van Palenstein Helderman W. PUFA-An index of clinical consequences of untreated dental caries. Community Dent Oral Epidemiol. 2010 Feb;38(1):77-82. doi: 10.1111/j.1600-0528.2009.00514.x.

17. Sofola $\mathrm{OO}$, Folayan MO, Oginni AB. Changes in the prevalence of dental caries in primary school children in Lagos State, Nigeria. Niger J Clin Pract. 2014;17(2):127-33. doi: 10.4103/1119-3077.127419.

18. Al-Darwish M, El Ansari W, Bener A. Prevalence of dental caries among 12-14 year old children in Qatar. Saudi Dent J. 2014 Jul;26(3):115-25. doi: 10.1016/j.sdentj.2014.03.006.

19. Sánchez-Pérez L, Irigoyen M, Zepeda M. Dental caries, tooth eruption timing and obesity: a longitudinal study in a group of Mexican schoolchildren. Acta Odontol Scand. 2010 Jan;68(1):57-64 doi: 10.3109/00016350903449367.

20. Sheiham A, James WP. Diet and dental caries: the pivotal role of free sugars reemphasized. J Dent Res. 2015 Oct;94(10):1341-7. doi: 10.1177/0022034515590377.

21. Vadiakas G, Oulis CJ, Tsinidou K, Mamai-Homata E, Polychronopoulou A. Socio-behavioural factors influencing oral health of 12 and 15 year old Greek adolescents. A national pathfinder survey. Eur Arch Paediatr Dent. 2011 Jun;12(3):139-45. doi: 10.1007/BF03262795.

22. Simón-Soro A, Mira A. Solving the etiology of dental caries. Trends Microbiol. 2015 Feb;23(2):76-82. doi: 10.1016/j.tim.2014.10.010.

23. Armfield JM, Mejia GC, Jamieson LM. Socioeconomic and psychosocial correlates of oral health. Int Dent J. 2013 Aug;63(4):202-9. doi: 10.1111/idj.12032. 
24. Lamerz A, Kuepper-Nybelen J, Wehle C, Bruning N, Trost-Brinkhues G, Brenner H, et al. Social class, parental education, and obesity prevalence in a study of six-year-old children in Germany. Int J Obes (Lond). 2005 Apr;29(4):373-80. doi: 10.1038/sj.ijo.0802914.

25. Schwendicke F, Dörfer CE, Schlattmann P, Foster Page L, Thomson WM, Paris S. Socioeconomic inequality and caries: a systematic review and meta-analysis. J Dent Res. 2015 Jan;94(1):10-8. doi: $10.1177 / 0022034514557546$.

26. Yang $F$, Zhang $Y$, Yuan $X, Y u$ J, Chen $S$, Chen Z, et al. Caries experience and its association with weight status among 8-year-old children in Qingdao, China. J Int Soc Prev Community Dent. 2015;5(1):52-8. doi: 10.4103/2231-0762.151978.

27. Figueiredo MJ, de Amorim RG, Leal SC, Mulder J, Frencken JE. Prevalence and severity of clinical consequences of untreated dentine carious lesions in children from a deprived area of Brazil. Caries Res. 2011;45(5):435-42. doi: 10.1159/000330531.

28. United States. General Accounting Office. Oral Health: dental disease is a chronic problem among low-income populations: report to congressional requesters. Washington: GAO/HEHS-0o-72; 2000.

29. Naidu RS, Boodoo D, Percival T, Newton JT. Dental emergencies presenting to a universitybased paediatric dentistry clinic in the West Indies. Int J Paediatr Dent. 2005 May;15(3):177-84. doi: 10.1111/j.1365-263X.2005.00625.X.

30. Hayden C, Bowler JO, Chambers S, Freeman R, Humphris G, Richards D, et al. Obesity and dental caries in children: a systematic review and meta-analysis. Community Dent Oral Epidemiol. 2013 Aug;41(4):289-308. doi: 10.1111/cdoe.12014.

31. Powell JC, Koroluk LD, Phillips CL, Roberts MW. Relationship between adjusted body mass index percentile and decayed, missing, and filled primary teeth. J Dent Child (Chic). 2013;80(3):115-20.

32. Sheller B, Churchill SS, Williams BJ, Davidson B. Body mass index of children with severe early childhood caries. Pediatr Dent. 2009;31(3):216-21.

33. Bafti LS, Hashemipour MA, Poureslami H, Hoseinian Z. Relationship between body mass index and tooth decay in a population of 3-6-year-old children in Iran. Int J Dent. 2015;2015:126530. doi: $10.1155 / 2015 / 126530$.

34. Armfield JM, Mejia GC, Jamieson LM. Socioeconomic and psychosocial correlates of oral health. Int Dent J. 2013 Aug;63(4):202-9. doi: 10.1111/idj.12032.

35. Olatosi 00, Onyejaka NK, Oyapero A, Ashaolu JF, Abe A. Age and reasons for first dental visit among children in Lagos, Nigeria. Niger Postgrad Med J. 2019;26(3):158-63. doi: 10.4103/npmj.npmj_60_19. 